\title{
Neuroprotective properties of curcumin in toxin-base animal models of Parkinson's disease: a systematic experiment literatures review
}

Xin-Shi Wang ${ }^{1 \dagger}$, Zeng-Rui Zhang ${ }^{1 \dagger}$, Man-Man Zhang ${ }^{1}$, Miao-Xuan Sun ${ }^{3}$, Wen-Wen Wang ${ }^{2^{*}}$ and Cheng-Long Xie

\begin{abstract}
Background: Curcumin (diferuloylmethane), a polyphenol extracted from the plant Curcuma longa, is widely used in Southeast Asia, China and India in food preparation and for medicinal purposes. Meanwhile, the neuroprotective actions of curcumin have been documented for experimental therapy in Parkinson's disease (PD).

Methods: In this study, we used a systematic review to comprehensively assess the efficacy of curcumin in experimental PD. Using electronic and manual search for the literatures, we identified studies describing the efficacy of curcumin in animal models of PD.

Results: We identified 13 studies with a total of 298 animals describing the efficacy of curcumin in animal models of PD. The methodological quality of all preclinical trials is ranged from 2 to 5 . The majority of the experiment studies demonstrated that curcumin was more significantly neuroprotection effective than control groups for treating PD. Among them, five studies indicated that curcumin had an anti-inflammatory effect in the PD animal models $(p<0.05)$. Meanwhile, four studies showed the antioxidant capability of curcumin, by which it protected substantia nigra neurons and improved striatal dopamine levels. Furthermore, two studies in this review displayed that curcumin treatment was also effective in reducing neuronal apoptosis and improving functional outcome in animal models of PD. Most of the preclinical studies demonstrated the positive findings while one study reported that curcumin had no beneficial effects against Mn-induced disruption of hippocampal metal and neurotransmitter homeostasis.
\end{abstract}

Conclusions: The results demonstrated a marked efficacy of curcumin in experimental model of PD, suggesting curcumin probably a candidate neuroprotective drug for human PD patients.

Keywords: Curcumin, Parkinson's disease, Preclinical studies, Animal models, Systematic review

\section{Background}

Parkinson disease (PD), a chronic progressive neurodegenerative disorder predominantly affecting elderly people, is mainly characterized by resting tremor, rigidity, bradykinesia, postural instability and gait disorder [1]. It is supposed that about 6 to 10 million people worldwide

\footnotetext{
*Correspondence: www15968766812@163.com; cl_xie1987@sohu.com ${ }^{\dagger}$ Equal contributors

${ }^{2}$ The center of Traditional Chinese Medicine, The Second Affiliated Hospital and Yuying Childrens Hospital of Wenzhou Medical University, Wenzhou 325027, China

'Department of Neurology, The First Affiliated Hospital of Wenzhou Medical University, Wenzhou 325000, China

Full list of author information is available at the end of the article
}

have suffered from PD, involving all ethnicities and races [2]. The quantity of individuals affected by PD increases rapidly with age, affecting approximately $1 \%$ of the population over sixty years and $4 \%$ of those over eighty years [3]. As the mean age of the population rises, the prevalence of individuals worldwide is predicted to be doubled by 2030 [4]. At present, supplemental dopamine remains the primary therapy way that can adequately improve functional capacity and quality of life in PD [2]. Nevertheless, most patients develop related motor complications after five years of administration, including L-dopainduced dyskinesia and motor fluctuations [5]. Surgical techniques like deep brain stimulation (DBS) can improve 
advanced symptoms and presentations and is regarded to exceed the best medical therapy. But, regrettably, less than $5 \%$ of the PD subjects may be qualified for such operations [5]. Consequently, there has been an emerging interest in the use of novel therapeutic strategies and natural antioxidants or plant molecules with neuroprotective characters are being developed for add-on therapy for PD patients.

Curcumin (diferuloylmethane) is widely used in Southeast Asia, India and China in food preparation or for medical purposes [6]. Moreover, it shows anti-oxidant, anti-inflammatory and anti-cancer features. It crosses the blood-brain barrier and is neuroprotective in central neurological disease [7]. Among them, the most pivotal biological function of curcumin related to neuroprotection is its anti-oxidant effect, which can guards substantia nigra $(\mathrm{SN})$ neurons and increases striatal dopamine count and chelates $\mathrm{Fe}^{2+}$ in the 6-OHDA (6-hydroxydopamine) rat models of $\mathrm{PD}$ [8]. What is more, consequent to its anti-oxidant activity, curcumin also exerts mitochondrial protection in various PD models. Recently, several studies in different experimental models of PD have showed neuroprotective effect of curcumin. For instance, one study had recently demonstrated that chronic dietary consumption of turmeric offers neuroprotection in toxic mouse model of PD [9]. Wang et al. reported that curcumin administration restored mitochondrial membrane potential, increased $\mathrm{Cu} / \mathrm{Zn}$ SOD (Superoxide Dismutase) and restored cell viability in 6OHDA-lesioned MES (mouse embryonic stem) 23.5 cells [10]. Similarly, Rajeswari and colleagues had showed an increase in striatal dopamine and DOPAC (3,4-Dihydroxyphenylacetic acid) levels following curcumin injection in MPTP (1-methyl-4-phenyl-1, 2,3,6-tetrahydropyridine) injected mice [11]. To some extent, animal experiments may give insights into the mechanisms of $\mathrm{PD}$, but a single study can not fully uncover all the details. Moreover, no clinical studies have tested the benefits of curcumin in PD patients. Hence, the exquisite benefits of curcumin in human PD are not well understand at present. The aim of this review was to systematicly describe the therapeutic potential of curcumin in animal models of PD and hope to provide more comprehensive assessment of the effects.

\section{Methods}

We implemented this systematic review based on the modified Preferred Reporting Items for Systematic Reviews and Meta-Analyses (PRISMA) Statement.

\section{Search strategy}

A carefully literatures search was performed to seek publications studying the effect of curcumin treatment on animal models of PD from Google scholar, PubMed, Chinese National Knowledge Infrastructure (CNKI),
Wanfang and VIP information database. The time is from the inception of individual database up to February 2016 for all English or Chinese language publications. The following search strategy was used for each database.

1. Curcumin

2. Turmeric

3. Carcuma Longa

4. or $/ 1-3$

5. Parkinson's disease

6. Parkinson disease

7. $\mathrm{PD}$

8. or $/ 5-7$

9. 4 and 8

In this study, two experienced reviewers (WWW and ZRZ) selected the qualified studies independently by browsing the abstracts or full texts based on the eligibility criteria. Divergences were resolved by consensus with a third party (CLX).

\section{Inclusion and exclusion criteria}

Inclusion criteria were pre-established as the following:

(1) Controlled researches assessing in vivo administration of curcumin to animals with PD;

(2)Laboratory animals of any species, age, gender, or strain to induced PD models were included; (3) Any kind of curcumin intervention that was compared with placebo control was included. Formulation, dosage, route of treatment, and curcumin therapy time were not limited;

(3) Original data being independent from other studies and no outcome measure restrictions were imposed.

Pre-established exclusion criteria were including:

(1) Case reports, editorials, abstracts, reviews, letters, end game or comments et al.;

(2)Not testing the efficacy of curcumin on PD models;

\section{Data extraction and quality assessment}

Two authors separately performed data collection, with disputes resolved by analysis and discussion. The detailed information from each study was listed as following: (1) Publication year, the first author name and experimental models; (2) Individual data were acquired from each animal, including number, weight, species, sex, anesthetic used, method used to induce PD models et al.; (3) Finally, route of administration, duration of treatment and dosage and outcome measures were also excerpt. We assessed the risk of bias of the included 
basic researches by applying a six-item modified scale according to our previous study [12].

\section{Results}

\section{Results of the search}

Based on our searches of the electronic databases and after removing reproduction we identified a total of 113 references. After looking through the titles and abstracts, we eliminated 65 papers with at least one of following reasons: (1) Case report, comments, reviews, or editorials; (2) Human trials. And finally, after reading the whole text of the remaining 48 studies which reported the efficacy of curcumin in animal models of PD, we incorporated 13 articles and assessed these for eligibility [11, 13-24] (Fig. 1).

\section{Study characteristics}

In this review, 13 studies involved 298 animals (Curcumin 173, control 125) from two species and five varieties: C57BL/6 mice $(n=6)$,Sprague-Dawley rats $(n=2)$, Swiss albino mice $(n=2)$, Wister rats $(n=2)$ and ICR (Imprinting Control Region) strain mice $(n=1)$. The studies varied in size, involving $12-40$ animals. The rats and mice weighted 200-300 g and 20$55 \mathrm{~g}$, respectively. Twelve studies utilized male animals and the remaining one used the female rats to perform the experiments. Five out of thirteen studies (38.4\%) were 1-methyl-4-phenyl-1,2,3,6-tetrahydropyridine (MPTP) models, and other four studies (30.7\%) utilized 6-OHDA lesioned models. The remaining four studies were using BSO (Buthionine sulfoximine) induced, homocysteine injected intracerebroventricularly, lipidosome induced and inhalation Mn induced PD models, respectively. Meanwhile, pentobarbital were used in 3 studies (23.1\%), 10\% Chloral hydrate in 2 study (15.4\%), isofiuorane in 1 study (7.7), while no report of anesthetics in the remaining 7 studies (53.8\%). Two studies performed a dose gradient of curcumin in the included studies, of which one study adopt 5, 50, $150 \mathrm{mg} / \mathrm{kg}$ dissolve in 1\% DMSO (intraperitoneally, i.p.) and the other one utilized 500 and 1500 PPM (Parts per million). Unfortunately, most studies did not show the curcumin purity in the paper. Meanwhile, in this review, 7 studies showed curcumin to be dissolved in DMSO, 4 studies in saline, 1 study in cremophor, and the remaining 1 to be supplemented in the diet (food pellets). Moreover, the method of IHC (Immunohistochemistry) or IFC (Immunofluorescence) was used as the molecular biology techniques in 7 studies, HPLC (High-performance liquid chromatography) analysis in 5 studies, western blot in 5 studies, and RT-PCR (Reverse transcription-

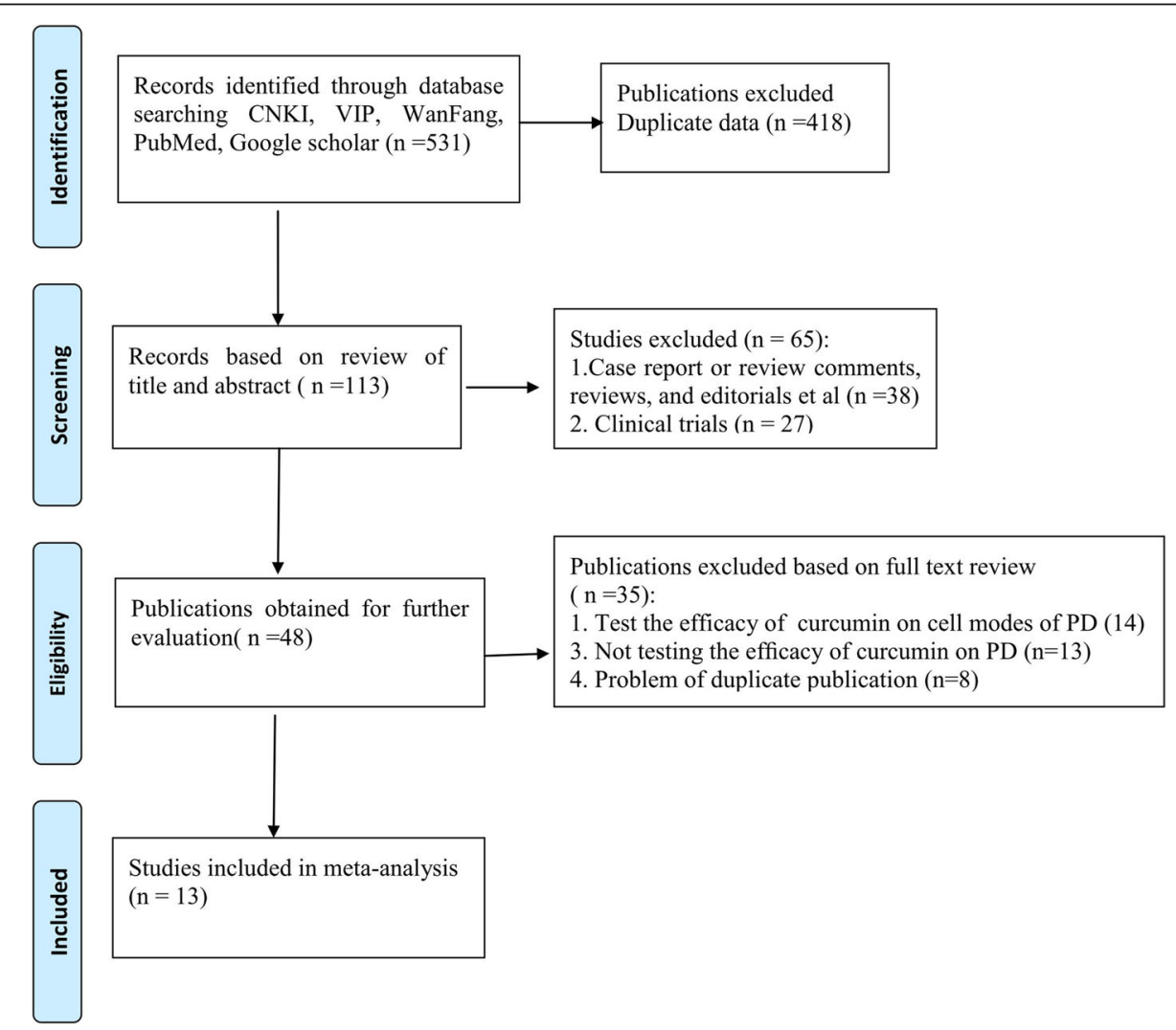

Fig. 1 Algorithm of study selection and inclusion in the meta-analysis 
polymerase chain reaction) in 2 studies in this review. To our knowledge, IHC and HPLC were probably used to investigate the neuroprotective effects whereas techniques of Western blotting and RT-PCR were likely used to investigate the potential mechanisms involved in the neuroprotective effects. The basic characteristics of the 13 studies are shown in Table 1.

\section{Risk of bias}

The risk of bias of included studies were ranged from 2 to 5 out of a total 6 points. Two studies got 2 points (15.4\%); six studies got 3 points (46.1\%); four studies got 4 points $(30.7 \%)$; one study got 5 points $(7.8 \%)$. The risk of bias of the 13 studies are shown in Table 2 .

\section{Neuroprotective mechanisms of curcumin}

Table 3 showed the main outcome measures and results of included studies. TH-positive (Tyrosine hydroxylase) cells or TH mRNA level in substantia Nigra was tested in 7 studies; striatal concentration of DA (Dopamine) and its metabolites DOPAC and HVA (Homovanillic acid) were inspected in 6 studies. Meanwhile, four studies investigated GFAP (Glial fibrillary acidic protein) expression in the striatum as an indicator of astrocyte activation; two studies tested TNF-a (Tumor necrosis factor) level and iron-deposition, respectively. Moreover, one study showed the levels of GSH (Glutathione), ROS (Reactive oxygen species), MAO-B (Monoamine Oxidase-B) activity, NF-k $\beta$, IL-1b (Interleukin), SOD1

Table 1 Basic information of included studies

\begin{tabular}{|c|c|c|c|c|}
\hline Study (years) & Species $($ Sex,n) & Model, anesthetic, weight & Interventions & Research methods \\
\hline $\begin{array}{l}\text { Virginia } \\
2005\end{array}$ & $\begin{array}{l}\text { SD Rats } \\
(\text { Male,6/6) }\end{array}$ & $\begin{array}{l}\text { 6-OHDA induced } \\
(12 \mu \mathrm{g}, \text { s.i.) } \\
\text { Isofiuorane, } 200 \mathrm{~g}\end{array}$ & $\begin{array}{l}\text { Curcumin }(50 \mathrm{mg} / \mathrm{kg} \text { dissolve in } 10 \% \text { of } \\
\text { Cremophor, gavage) for } 4 \text { days prior to I } \\
\text { esioning }\end{array}$ & $\begin{array}{l}\text { 1. IHC } \\
\text { 2. HPLC analysis }\end{array}$ \\
\hline Pan 2007 & $\begin{array}{l}\text { C57BL/6 mice } \\
\text { (Male,30/10) }\end{array}$ & $\begin{array}{l}\text { MPTP induced } \\
(30 \mathrm{mg} / \mathrm{kg} \text {, i.p.), } \\
\text { Pentobarbital, } 20 \mathrm{~g}\end{array}$ & $\begin{array}{l}\text { Curcumin }(5,50,150 \mathrm{mg} / \mathrm{kg} \text { dissolve in } 1 \% \\
\text { DMSO, i.p., respectively) for } 4 \text { days after surgery }\end{array}$ & $\begin{array}{l}\text { 1. IHC } \\
\text { 2. WB analysis }\end{array}$ \\
\hline $\begin{array}{l}\text { Balusamy } \\
2008\end{array}$ & $\begin{array}{l}\text { C57BL/6 mice } \\
\text { (Male,6/6) }\end{array}$ & $\begin{array}{l}\text { BSO induced } \\
(3 \mathrm{mmol} / \mathrm{kg} \text {, i.p.), } \\
\mathrm{NR}, 25 \mathrm{~g}\end{array}$ & $\begin{array}{l}\text { Curcumin } \\
(50 \mathrm{mg} / \mathrm{kg} \text { dissolve in saline, i.p., bw per } \\
\text { day, for } 1 \text { and } 3 \text { days) }\end{array}$ & 1. WB analysis \\
\hline $\begin{array}{l}\text { Rajeswari } \\
2008\end{array}$ & $\begin{array}{l}\text { Swiss albino mice } \\
\text { (Male, 8/8) }\end{array}$ & $\begin{array}{l}\text { MPTP induced } \\
\text { (40 } \mathrm{mg} / \mathrm{kg} \text {, i.p.), } \\
\text { NR, } 25-30 \mathrm{~g}\end{array}$ & $\begin{array}{l}\text { Curcumin ( } 80 \mathrm{mg} / \mathrm{kg} \text { dissolve in DMSO, i.p.) } \\
\text { for } 7 \text { days after surgery }\end{array}$ & 1. HPLC analysis \\
\hline $\begin{array}{l}\text { Wang } \\
2009\end{array}$ & $\begin{array}{l}\text { C57BL/6 mice } \\
\text { (Male,10/10) }\end{array}$ & $\begin{array}{l}\text { MPTP induced } \\
(60 \mathrm{mg} / \mathrm{kg} \text {, i.p.), } \\
\text { NR, } 25-30 \mathrm{~g}\end{array}$ & $\begin{array}{l}\text { Curcumin ( } 15 \mathrm{mg} / \mathrm{kg} \text { dissolve in DMSO, i.p.) } \\
\text { for } 4 \text { days prior to lesioning and after surgery }\end{array}$ & $\begin{array}{l}\text { 1. RT-PCR } \\
\text { 2. HPLC analysis }\end{array}$ \\
\hline Song 2010 & $\begin{array}{l}\text { C57BL/6 mice } \\
\text { (Male, } 10 / 10)\end{array}$ & $\begin{array}{l}\text { MPTP induced } \\
\text { (30 } \mathrm{mg} / \mathrm{kg} \text {, i.p.), } \\
\text { NR, 23-25 g }\end{array}$ & $\begin{array}{l}\text { Curcumin ( } 50 \mathrm{mg} / \mathrm{kg} \text { dissolve in DMSO, i.p.) } \\
\text { for } 5 \text { days after surgery }\end{array}$ & $\begin{array}{l}\text { 1. Behavioral tests and WB } \\
\text { 2. } I H C\end{array}$ \\
\hline Peng 2010 & $\begin{array}{l}\text { SD Rats } \\
\text { (Male,20/20) }\end{array}$ & $\begin{array}{l}\text { 6-OHDA induced } \\
(16 \mu \mathrm{g}, \text { s.i. }) \text {, } \\
\text { Pentobarbital, } 200-250 \mathrm{~g}\end{array}$ & $\begin{array}{l}\text { Curcumin ( } 100 \mathrm{mg} / \mathrm{kg} \text { dissolve in DMSO, gavage) } \\
\text { for } 4 \text { weeks after surgery }\end{array}$ & $\begin{array}{l}\text { 1. Behavioral tests } \\
\text { 2. HPLC analysis }\end{array}$ \\
\hline Zahra 2012 & $\begin{array}{l}\text { Wister rats } \\
\text { (Male,8/8) }\end{array}$ & $\begin{array}{l}\text { Homocysteine induced } \\
(2 \mathrm{~mol} / \mathrm{l}, \text { i.c.v.), NR, } 250- \\
300 \mathrm{~g}\end{array}$ & $\begin{array}{l}\text { Curcumin ( } 50 \mathrm{mg} / \mathrm{kg} \text { dissolve in saline, i.p.) for } 10 \\
\text { days beginning } 5 \text { days prior to Hcy injection }\end{array}$ & $\begin{array}{l}\text { 1. Behavioral tests } \\
\text { 2. IHC and Tunel staining }\end{array}$ \\
\hline Du 2012 & $\begin{array}{l}\text { Wister rats } \\
\text { (Female,12/12) }\end{array}$ & $\begin{array}{l}\text { 6-OHDA induced } \\
(20 \mu \mathrm{g} \text {, s.i.), } \\
\text { Chloral hydrate, } 200-220 \mathrm{~g}\end{array}$ & $\begin{array}{l}\text { Curcumin pretreatment }(200 \mathrm{mg} / \mathrm{kg} \text { dissolve in } \\
\text { saline) twice } \\
\text { a day for } 24 \text { days in total }\end{array}$ & $\begin{array}{l}\text { 1. HPLC analysis } \\
\text { 2. } I H C\end{array}$ \\
\hline Yu 2012 & $\begin{array}{l}\text { C57BL/6 mice } \\
\text { (Male, } 10 / 10)\end{array}$ & $\begin{array}{l}\text { MPTP induced } \\
\text { (30 mg/kg, i.p.), } \\
\text { NR, } 25 \mathrm{~g}\end{array}$ & $\begin{array}{l}\text { Curcumin }(50 \mathrm{mg} / \mathrm{kg} \text { dissolve in saline, i.p.) for } \\
5 \text { days } \\
\text { after surgery }\end{array}$ & $\begin{array}{l}\text { 1. Behavioral tests and WB 2. IHC } \\
\text { and iron staining }\end{array}$ \\
\hline Guo 2012 & $\begin{array}{l}\text { C57BL/6 mice } \\
\text { (Male,30/10) }\end{array}$ & $\begin{array}{l}\text { Lipidosome induced } \\
(1 \mu \mathrm{g} / \mathrm{ml}, \mathrm{s.i} .) \text {, Chloral } \\
\text { hydrate, } 18-22 \mathrm{~g}\end{array}$ & $\begin{array}{l}\text { Curcumin }(10,20,40 \mathrm{mg} / \mathrm{kg} \text { dissolve in } 1 \% \\
\text { DMSO, respectively, i.p.) for } 4 \text { days after surgery }\end{array}$ & $\begin{array}{l}\text { 1. Behavioral tests and WB 2. Elisa, } \\
\text { RT-PCR, IFC 3. Luciferase assay }\end{array}$ \\
\hline $\begin{array}{l}\text { Tripanichkui } \\
2013\end{array}$ & $\begin{array}{l}\text { ICR strain mice } \\
\text { (Male,7/7) }\end{array}$ & $\begin{array}{l}\text { 6-OHDA induced } \\
(33 \mu g, \text { s.i.), } \\
\text { Pentobarbital, NR }\end{array}$ & $\begin{array}{l}\text { Curcumin ( } 200 \mathrm{mg} / \mathrm{kg} \text { dissolve in DMSO, i.p.) for } \\
7 \text { days after surgery }\end{array}$ & 1. IHC 2. Quantification Kits \\
\hline Ariana 2014 & $\begin{array}{l}\text { Swiss albino mice } \\
\text { (Male, 16/8) }\end{array}$ & $\begin{array}{l}\text { Inhalation Mn induced, } \\
\mathrm{NR}, 45-55 \mathrm{~g}\end{array}$ & $\begin{array}{l}\text { Curcumin ( } 500 \text { or } 1500 \text { PPM) was supplemented } \\
\text { in the diet for } 14 \text { weeks }\end{array}$ & $\begin{array}{l}\text { 1. Behavioral tests } 2 \text {. } \\
\text { Neurochemical Analysis }\end{array}$ \\
\hline
\end{tabular}

MPTP 1-methyl-4-phenyl-1, 2,3,6-tetrahydropyridine; SD Rats Sprague-Dawley rats; BSO Buthionine sulfoximine; 6-OHDA 6-hydroxy dopamine; NR no report; s.i. Striatum injection; i.p. intraperitoneally; i.c.v. intracerebroventricularly; DMSO Dimethyl sulfoxide; PBS Phosphate-buffered saline; IHC Immunohistochemistry; HPLC High-performance liquid chromatography; WB analysis western blot; $R T$-PCR Reverse transcription-polymerase chain reaction; IFC immunofluorescence; Elisa the enzyme-linked immunosorbent assay 
Table 2 Risk of bias of included studies

\begin{tabular}{|c|c|c|c|c|c|c|c|c|c|c|c|c|c|}
\hline Study & $\begin{array}{l}\text { Virginia } \\
2005\end{array}$ & $\begin{array}{l}\text { Pan } \\
2007\end{array}$ & $\begin{array}{l}\text { Balusamy } \\
2008\end{array}$ & $\begin{array}{l}\text { Rajeswar } \\
2008\end{array}$ & $\begin{array}{l}\text { Wang } \\
2009\end{array}$ & $\begin{array}{l}\text { Song } \\
2010\end{array}$ & $\begin{array}{l}\text { Peng } \\
2010\end{array}$ & $\begin{array}{l}\text { Zahra } \\
2012 \\
\end{array}$ & $\begin{array}{l}\text { Du } \\
2012\end{array}$ & $\begin{array}{l}\text { Yu } \\
2012\end{array}$ & $\begin{array}{l}\text { Guo } \\
2012 \\
\end{array}$ & $\begin{array}{l}\text { Tripanichkui } \\
2013\end{array}$ & $\begin{array}{l}\text { Ariana } \\
2014 \\
\end{array}$ \\
\hline $\bar{A}$ & $\sqrt{ }$ & $\sqrt{ }$ & $\sqrt{ }$ & $\sqrt{ }$ & $\sqrt{ }$ & $\sqrt{ }$ & $\sqrt{ }$ & $\sqrt{ }$ & $\sqrt{ }$ & $\sqrt{ }$ & $\sqrt{ }$ & $\sqrt{ }$ & $\sqrt{ }$ \\
\hline B & $\sqrt{ }$ & & & & $\sqrt{ }$ & & & $\sqrt{ }$ & $\sqrt{ }$ & $\sqrt{ }$ & $\sqrt{ }$ & $\sqrt{ }$ & $\sqrt{ }$ \\
\hline C & $\sqrt{ }$ & & & & & & & & & & & & \\
\hline \multicolumn{14}{|l|}{$D$} \\
\hline$E$ & $\sqrt{ }$ & $\sqrt{ }$ & $\sqrt{ }$ & $\sqrt{ }$ & $\sqrt{ }$ & $\sqrt{ }$ & $\sqrt{ }$ & $\sqrt{ }$ & $\sqrt{ }$ & $\sqrt{ }$ & $\sqrt{ }$ & $\sqrt{ }$ & $\sqrt{ }$ \\
\hline $\mathrm{T}$ & $\sqrt{ }$ & & $\sqrt{ }$ & $\sqrt{ }$ & & $\sqrt{ }$ & & $\sqrt{ }$ & $\sqrt{ }$ & & & $\sqrt{ }$ & $\sqrt{ }$ \\
\hline Total & 5 & 2 & 3 & 3 & 3 & 3 & 2 & 4 & 4 & 3 & 3 & 4 & 4 \\
\hline
\end{tabular}

A: peer reviewed publication; B:random allocation to group; C: blinded assessment of outcome; D: a sample size calculation; E: compliance with animal welfare regulations; F: a statement of a potential conflict of interest

Table 3 Main outcome measures of included studies

\begin{tabular}{lll}
\hline Study (years) & Outcome measures & Neuroprotection mechanism \\
\hline Virginia 2005 & 1. TH-positive cells in the SN were increased by curcumin. & Phenomenon research. \\
Pan 2007 & 2. Striatal concentration of DA and its metabolites DOPAC and HVA & Anti-oxidant and anti-inflammatory. \\
Balusamy 2008 & 2. GFAP-positive cells and iNOS level in the SNpc & Anti-oxidant capabilities.
\end{tabular}

Rajeswari 2008

Wang 2009

Song 2010

Peng 2010

Zahra 2012

Du 2012

Yu 2012

Guo 2012

Tripanichkui 2013

Ariana 2014
2. Accumulation of ROS was prevented only by pretreatment with curcumin.

1. Curcumin reversed the reduction in striatal DA and DOPAC levels;

2. MAO-B activity was reduced by curcumin treatment

1. Curcumin reversed the reduction in $\mathrm{SNpc} \mathrm{TH}$ and DAT mRNA levels;

2. DA and DOPAC levels were restored by curcumin

1. Curcumin showed a significant increase in locomotion frequencies;

2. Curcumin increased the TH, DAT level and inhibits

astrocyte activation in terms of GFAP.

3. Inhibitory effects of curcumin on JNK, c-Jun, and caspase-3.

1. Curcumin could ameliorate rotational behaviour;

2. DA level was restored by curcumin administration.

1. Curcumin prevented the decrease of locomotor activity.

2. The number of Nissl neurons on the left side of substantia nigra

was significantly higher in curcumin group.

3. Effect of curcumin on Bax/BCl-2.

1. Curcumin partly restored the levels of DA, DOPAC and HVA.

2. TH-positive neurons were restored by curcumin pretreatment.

3. Marked decrease of iron-positive cells was found in the curcumin pretreatment group.

1. Curcumin ameliorated open-field test;

2. TH, DAT levels were restored by curcumin and inhibited

GFAP and TNF-a.

1. Motor coordination of rota-rod test and hanging test were improved in the curcumin treatment group.

2. Curcumin suppressed nuclear translocation and NF-K $\beta$ activity.

3 TNF-a and IL-1b were restored by curcumin.

1. Curcumin attenuated loss of TH fibers, diminished activation of GFAP and microgliosis, sustained SOD1 level.

1.Curcumin produced similar deleterious effects in the beam-walking test and single-pellet test. 2. Curcumin showed no

beneficial effects against Mn-induced disruption of hippocampal metal and neurotransmitter homeostasis (DA or serotonin).
Anti-oxidant capabilities.

Phenomenon research.

Anti-inflammatory and anti-apoptosis.

Phenomenon research.

Anti-apoptosis.

Suppress the iron-induced degeneration.

Anti-inflammatory.

Anti-inflammatory

Anti-inflammatory and anti-oxidant

No neuroprotection

TH Tyrosine hydroxylase; SN Substantia Nigra; DA dopamine; DOPAC 3,4-Dihydroxyphenylacetic acid; HVA Homovanillic acid; iNOS Inducible nitric oxide synthase; GFAP Glial fibrillary acidic protein; GSH Glutathione; ROS Reactive oxygen species; MAO-B Monoamine oxidase-B; DAT dopamine transport; JNK c-Jun N-terminal kinase; SOD Superoxide Dismutase; TNF- $\alpha$ Tumor necrosis factor; IL-1 $\beta$ Interleukin-1 $\beta$ 
and metal Mn, separately. Fig. 2 showed the neuroprotective mechanism of curcumin (Fig. 2).

\section{Curcumin exhibites anti-inflammatory property}

Five studies indicated that curcumin had antiinflammatory effect on the PD animal models. Pan et al. [14], Yu et al. [21] and Tripanichkui et al. [23] reported that curcumin could diminished the GFAP level compared with control group $(p=0.002)$. Yu S et al. [17] demonstrated that MPTP -treated mice exhibited 2.5 times more activated astrocytes than the control mice $(p<0.01)$. MPTP plus curcumin treatment obviously relieved the MPTP-induced increase in the amount of activated astrocytes $(p<0.01)$. Moreover, Guo et al. [22] displayed that curcumin suppressed nuclear translocation and NF-k $\beta$ activity, as well as reduced the levels of TNF-a and IL-1b $(P<0.05)$.

\section{Curcumin is used as an antioxidant}

Four studies showed the anti-oxidant function of curcumin which protected SN neurons and improved striatal dopamine levels. Pan et al. [14] reported iNOS level in the $\mathrm{SNpc}$ was obvious reduced by curcumin treatment compared with MPTP group ( $p=0.005)$. Jagatha B et al. [15] demonstrated the neuroprotective fumnction of curcumin against GSH depletion-mediated oxidative stress in the cerebra. Intraperitoneal injection of curcumin resulted in a 2-fold increase in total brain GSH levels. Meanwhile, accumulation of ROS was avoided by pretreatment with curcumin. Rajeswari et al. displayed a significant decrease in MAO-B activity in the striatal region by curcumin treatment. Guo et al. [22] demonstrated that 6-OHDA significantly decreased SOD1 expression in the ipsilateral striatum $(p<0.05)$, which was impeded by curcumin $(p<0.05)$.

Curcumin treatment is effective in decreasing neuronal apoptosis and suppressing iron-deposition
In this review, two studies showed that curcumin administration was effective in decreasing neuronal

apoptosis as well as improving functional outcome in animal models of PD. Immunoblotting results of Yu S et al. [17] showed that MPTP induced an apparently increase in phosphorylated forms of JNK. Interestingly, curcumin administration (50 mg/kg for 7 days) overtly inhibited MPTP-induced JNK phosphorylation. Meanwhile, Zahra et al. [19] demonstrated Bax/Bcl2 ratio significantly increased in the control group, which was apparently reduced by curcumin administration $(p<0.001)$. Du et al. [20] reported that the quantity of iron-positive cells raised in the lesioned side compared with control. However, a striking decrease of ironpositive cells was discovered in the curcumin pretreatment group, compared to the 6-OHDA-lesioned group. Interestingly, only one study [24] showed that curcumin had no helpful effects against Mn-induced disruption of hippocampal metal and neurotransmitter homeostasis. Future studies are needed to confirm these results and investigate if other mechanisms are involved in Mn-induced experimental model of Parkinsonism.

\section{Discussion}

Thirteen preclinical trials with a total of 298 animals were included in the analysis. Our results indicated that, comparing with the placebo group, curcumin could improve the neurobehavioral function and restore the levels of TH, DA, DOPAC et al., suggesting that curcumin offers neuroprotection in animal models of PD probably via antioxidant capabilities, anti-inflammatory and anti-apoptosis. To our knowledge, there is no doubt that curcumin is helpful in the treatment of animal models of PD, but we are not aware of whether animal researches reliably inform human studies. Further evidence is necessary in this area by assessing curcumin in clinical

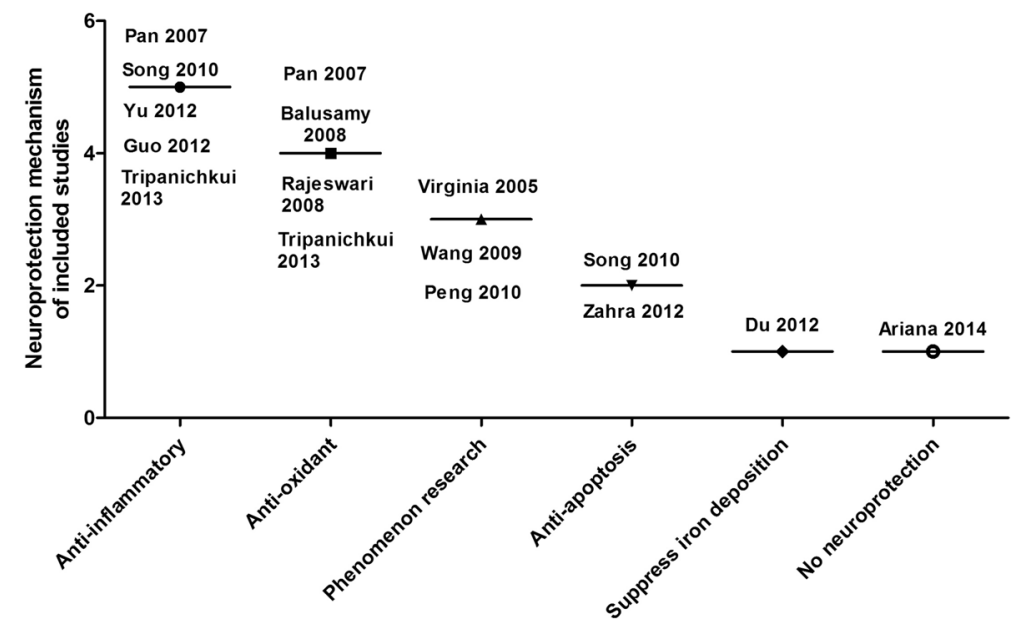

Fig. 2 Neuroprotection mechanisms for curcumin in treating Parkinson's disease 
trials. However, we should also note that the poor bioavalibility of curcumin will limit its clinical application.

\section{Neuroprotective mechanisms of curcumin in treating PD Curcumin exhibites anti-inflammatory property}

As shown in Fig. 3 that neuroprotection mechanisms for curcumin in treating PD are various (Fig. 3). Pretreatment or post-treatment of curcumin in 6-OHDAlesioned rats resulted in reduced DA neuron loss compared with placebo group and attenuated the loss of DOPAC and HVA acid in the striata [13]. Exactly, the neuroprotective function of curcumin against PD is related to its anti-oxidant capability. MES cells treated with curcumin remarkably augmented the expression of $\mathrm{Cu}-\mathrm{Zn}$ superoxide dismutase and decreased intracellular ROS accumulation [10]. Furthermore, accumulation of oxidative DNA damage has been uncovered in PD and transition metal ions such as $\mathrm{Cu}$ and Fe powerfully inhibit the DNA repair enzymes [25]. However, curcumin can changeover such inhibition of DNA repair enzymes both in neuroblastoma cells and in vitro [26]. Meanwhile, Rajeswari et al. showed that DA depletion and elevated monoamine oxidase- $B$ activity, as a function of MPTP-induced toxicity, was alleviated with curcumin. Obviously, the most important biological function of curcumin pertinent to neuroprotection is its antioxidant function.

\section{Curcumin is used as an antioxidant}

Treatment of curcumin in PD animal models evidently attenuated the loss of DA neurons in SN. The potential effects of curcumin on NO generations and associated signaling pathways in LPS-induced cell PD models had been preliminary investigated [27]. Additionaly, curcumin could weaken the generation or viability of prostaglandins, glutamate, and pro-inflammatory cytokines in rat's hypothalamus and reduce the levels of GFAP, a marker of astrocytic proliferation [28]. What is more, curcumin restored mitochondrial membrane potential and modulated NF-K $\beta$ nuclear translocation by inhibition of IL-6 and TNF-a [29]. Meanwhile, curcumin treatment abrogated dopamine-induced striatal neuron cell death by prevention of c-Jun phosphorylation and caspase 3 activation [17].

\section{Curcumin treatment is effective in reducing neuronal apoptosis}

Jaisin et al. depicted that the level of p53 was downregulated in SH-SY5Y cell lines using a 6-OHDAlesioned model by curcumin administration. The protection gained by curcumin treatment against 6-OHDA toxicity was because of the suppression of p53 phosphorylation and the restoration of balance between antiand pro-apoptotic proteins of Bcl-2 family [30]. One study have explicitly demonstrated that the molecular mechanism involved in the neuroprotection of curcumin against MPP +- mediated apoptosis in PC12 cells is via Bcl-2 signal pathway and decreased levels of proapoptotic proteins, Bax and Bad [31]. The survival rate of cells being treated with $0.25 \mathrm{mmol} / \mathrm{L}$ curcumin was $72 \%$ compared with $45 \%$ in MPTP alone. What is more, $\mathrm{Yu}$ and colleagues showed that curcumin suppressed JNK-mediated dopamine neuron apoptosis induced by $\mathrm{MPP}+$ exposure in both SH-SY5Y cell models and

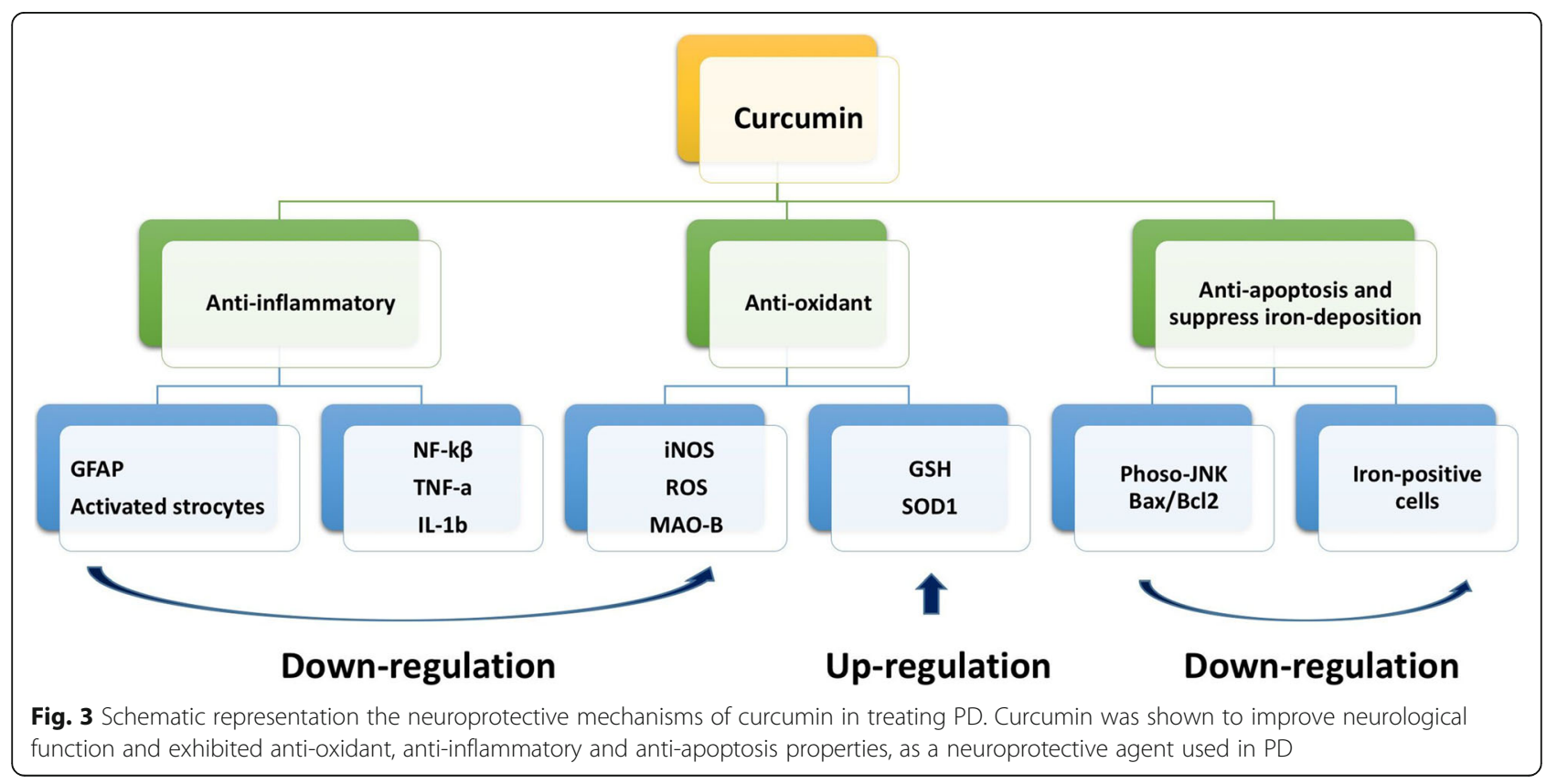


C57BL/6 mice [17]. Previous findings suggested that in addition to anti-oxidant and anti-inflammatory features, the function of curcumin in PD also is related to complex regulatory of cell-mediated apoptosis such as JNK pathway.

\section{Assessment of the risk of bias}

To our knowledge, there is no established valid and reliable tool to evaluate the risk of bias in animal studies, so the risk of bias assessments of each systematic review is inconsistent. To help overcome barriers in the switching of preclinical trials to clinical studies, the original Stroke Therapy Academic Industry Roundtable publication gave a recommendation for the preclinical development of acute ischemic stroke (AIS) [32]. Although recognized to be rational, they have not been closely followed or rigorously validated. Therefore, updated new and appropriate preclinical recommendations were urgent [33]. Though it was a recommendation for basic researches of supposed acute stroke therapies, the modified six-items from the suggestions could be regarded as a criterion for the risk of bias of animal studies for other models [34]. The new and amended preclinical suggestions may provide a basis for further consideration and careful discussions [33]. Overall, we believe that the standard suggestions were helpful in improving many features of preclinical testing. Meanwhile, one need realized that fulfilling them does not guarantee success in clinical development. Nonetheless, rigorous and thorough preclinical design could provide reassurance that there is potentially a greater chance for success in clinical trials.

\section{Implication for further studies}

Animal researches are an essential early step toward evaluating and developing an intervention for clinical trials in humans [35]. Systematic reviews have been supposed to be vital for translating the findings from preclinical researches to human studies. We believe that similar technique can be used to increase our comprehending of sources of bias in animal experiments as used in clinical trial, which will result in improvements in study quality [36]. To our knowledge, curcumin is a well-known drug for the treatment of PD researches in vitro. Although the present evidence is inadequate to support efficacy of curcumin in clinic, it is a promising candidate for furture PD patients. Nevertheless, subtherapeutic levels resulted from low bioavailability of orally curcumin continues to be the main hindrance of curcumin administration and poses great challenges to date. Meanwhile, various studies have demonstrated that curcumin is insoluble in aqueous solution, extremely unstable in alkaline condition, and very easily degraded and metabolized by human body. In this paper, 4 studies used saline to dissolve is unsuitable. Therefore, future researches with animal need to select suitable solvents. Several studies reported that the conversion of waterinsoluble curcumin into nano-sized particles or being dissolved in DMSO could greatly improve curcumin's solubility in vivo. In addition, other plant-derived polyphenols are also increasingly receiving attention as dietary supplements for the homeostatic management of central nervous system disorders. Similarly, the poor bioavailability of some polyphenols (such as silybin, green tea or proanthocyanidin) likely contributes to poor clinical trial. Based on this situation, in the future, more studies should focus on investigating new ways to improve bioavailability of curcumin and other polyphenols.

\section{Interpretation of the results}

Curcumin is a natural product with multiple biological function and plentiful potential therapeutic applications in neurological diseases [37]. In addition, more efforts are needed to make out how and why curcumin can have these pharmacological effects, taking into consideration its low bioavailability. By means of analyzing the similarities between the biological function of curcumin and its degradation products against central nervous disorders, it appears that the degradation products may contribute to the pharmacological effects of curcumin [38]. Meanwhile, recently, one research suggested that the degradation products should play a pivotal role in the diverse biological activities of curcumin [39]. This new finding not only offer novel insights into the complex pharmacology of curcumin due to its poor bioavailability, but also provide new approach for developing therapeutic applications of this natural product. Whatever, low systemic bioavailability of curcumin due to its low aqueous solubility and poor stability is a main disadvantage, which has severely limited its clinical application. To overcome this obstacle, experts have recently tried strategies to improve its bioavailability through various delivery systems including nanoparticles, liposomes, micelles, etc. [40]. Improved bioavailability, by various delivery systems or other means, is expected to bring improved bioefficacy in clinical application.

\section{Conclusions}

In this systematic review, curcumin, as a neuroprotective agent used in PD, exhibited anti-oxidant, antiinflammatory and anti-apoptosis properties, and was shown to improve neurological function. Several studies in different experimental models of PD strongly support the clinical trial application of curcumin in PD patients. However, we still need more welldesigned RCTs (Randomized controlled clinical trials) to ensure the efficacy of curcumin in PD patients. 


\section{Abbreviations}

6-OHDA: 6-hydroxydopamine; BSO: buthionine sulfoximine; DA: dopamine; DMSO: dimethylsulfoxide; DOPAC: 3,4-Dihydroxyphenylacetic acid; GFAP: glial fibrillary acidic protein; GSH: Glutathione; HPLC: high-performance liquid chromatography; HVA: homovanillic acid; ICR: imprinting Control Region; IFC: immunofluorescence; IHC: immunohistochemistry; IL-1b: interleukin; MAO-B: monoamine oxidase-B; MES: mouse embryonic stem; MPTP: 1methyl-4-phenyl-1,2,3,6-tetrahydropyridine; PD: Parkinson's disease; ROS: reactive oxygen species; RT-PCR: reverse transcription-polymerase chain reaction; SN: substantia nigra; SOD: superoxide dismutase; $\mathrm{TH}$ : tyrosine hydroxylase; TNF-a: tumor necrosis factor

\section{Funding}

The study was supported by the Projects of National Science Foundation of China (No. 81600977), National Key Technology Research and Development Program of the Ministry of Science and Technology of China (grant number: 2015BAl13B01) and Wenzhou Municipal Sci-Tech Bureau Program (Y20160002)

\section{Availability of data and materials}

The datasets and materials supporting the conclusions of this article are presented in this main paper.

\section{Authors' contributions}

WWW and ZRZ conceived and participated in its design, searched databases, XSW and MXS extracted and assessed studies and helped to draft the manuscript. MMZ helped in guiding and revising the manuscript. CLX participated in the conceptualization and design of the review and revised the review. All authors read and approved the final manuscript.

\section{Authors' Information}

1 Department of Neurology, The First Affiliated Hospital of Wenzhou Medical University, Wenzhou 325,000, China.

2 The center of Traditional Chinese Medicine, The Second Affiliated Hospital \& Yuying Children's Hospital of Wenzhou Medical University, 325,027, Wenzhou, China.

3. The center of rehabilitation, The First Affiliated Hospital of Wenzhou Medical University, Wenzhou 35,000, China.

\section{Ethics approval and consent to participate}

Not applicable.

\section{Consent for publication}

Not applicable.

\section{Competing interests}

The authors declare that they have no conflict of interest

\section{Publisher's Note}

Springer Nature remains neutral with regard to jurisdictional claims in published maps and institutional affiliations.

\section{Author details}

'Department of Neurology, The First Affiliated Hospital of Wenzhou Medical University, Wenzhou 325000, China. ${ }^{2}$ The center of Traditional Chinese Medicine, The Second Affiliated Hospital and Yuying Childrens Hospital of Wenzhou Medical University, Wenzhou 325027, China. ${ }^{3}$ The center of rehabilitation, The First Affiliated Hospital of Wenzhou Medical University, Wenzhou 325000, China.

Received: 6 February 2017 Accepted: 11 August 2017 Published online: 17 August 2017

\section{References}

1. Fahn S. Description of Parkinson's disease as a clinical syndrome. Ann N Y Acad Sci. 2003 Jun;991:1-14

2. Connolly BS, Lang AE. Pharmacological treatment of Parkinson disease: a review. JAMA. 2014 Apr 23-30;311(16):1670-83.

3. Driver JA, Logroscino G, Gaziano JM, Kurth T. Incidence and remaining lifetime risk of Parkinson disease in advanced age. Neurology. 2009 Feb 3; 72(5):432-8.
4. Dorsey ER, Constantinescu R, Thompson JP, Biglan KM, Holloway RG, Kieburtz K, Marshall FJ, Ravina BM, Schifitto G, Siderowf A, Tanner CM Projected number of people with Parkinson disease in the most populous nations, 2005 through 2030.Neurology. 2007 Jan 30;68(5):384-5. 5.Fahn S. The history of dopamine and levodopa in the treatment of Parkinson's disease. Mov Disord. 2008;23 Suppl 3:\$497-508.

5. Morgante L, Morgante F, Moro E, Epifanio A, Girlanda P, Ragonese P, Antonini A, Barone P, Bonuccelli U, Contarino MF, Capus L, Ceravolo MG, Marconi R, Ceravolo R, D'Amelio M, Savettieri G. How many parkinsonian patients are suitable candidates for deep brain stimulation of subthalamic nucleus? Results of a questionnaire. Parkinsonism Relat Disord 2007 Dec 13(8):528-531.

6. Aggarwal BB, Sundaram C, Malani N, Ichikawa H. Curcumin: the Indian solid gold. Adv Exp Med Biol. 2007;595:1-75.

7. Lee WH, Loo CY, Bebawy M, Luk F, Mason RS, Rohanizadeh R. Curcumin and its derivatives: their application in neuropharmacology and neuroscience in the 21st century. Curr Neuropharmacol. 2013,Jul;11(4):338-78.

8. Mythri RB, Bharath MM. Curcumin: a potential neuroprotective agent in Parkinson's disease. Curr Pharm Des. 2012;18(1):91-9.

9. Mythri RB, Harish G, Dubey SK, Misra K, Bharath MM. Glutamoyl diester of the dietary polyphenol curcumin offers improved protection against peroxynitritemediated nitrosative stress and damage of brain mitochondria in vitro: implications for Parkinson's disease. Mol Cell Biochem. 2011 Jan;347(1-2):135-43.

10. Wang J, Du XX, Jiang H, Xie JX. Curcumin attenuates 6-hydroxydopamineinduced cytotoxicity by anti-oxidation and nuclear factor-kappa B modulation in MES23.5 cells. Biochem Pharmacol. 2009 Jul 15;78(2):178-83.

11. Rajeswari A, Sabesan M. Inhibition of monoamine oxidase-B by the polyphenolic compound, curcumin and its metabolite tetrahydrocurcumin, in a model of Parkinson's disease induced by MPTP neurodegeneration in mice. Inflammopharmacology. 2008 Apr;16(2):96-9.

12. Macleod MR, O'Collins T, Howells DW, Donnan GA. Pooling of animal experimental data reveals influence of study design and publication bias. Stroke. 2004.May;35(5):1203-8.

13. Zbarsky V, Datla KP, Parkar S, Rai DK, Aruoma OI, Dexter DT. Neuroprotective properties of the natural phenolic antioxidants curcumin and naringenin but not quercetin and fisetin in a 6-OHDA model of Parkinson's disease Free Radic Res. 2005 Oct;39(10):1119-25.

14. Pan J, Ding J-q, Chen S-d. The protection of curcumin in nigral dopaminergic neuronal injury of mice model of Parkinson disease. Chin J Contemp Neurol Neurosurg. 2007 Oct;7(5):421-6.

15. Jagatha B, Mythri RB, Vali S, Bharath MM. Curcumin treatment alleviates the effects of glutathione depletion in vitro and in vivo: therapeutic implications for Parkinson's disease explained via in silico studies. Free Radic Biol Med. 2008 Mar 1;44(5):907-17.

16. Wang JY, Xu LZ. The research of the effect of curcumin on dopaminergic neurons in mouse model of parkinson's disease. Journal of Taishan Menicalcollege. 2009;30(8):564-6.

17. Yu S, Zheng W, Xin N, Chi ZH, Wang NQ, Nie YX, Feng WY, Wang ZY. Curcumin prevents dopaminergic neuronal death through inhibition of the c-Jun N-terminal kinase pathway. Rejuvenation Res. 2010 Feb;13(1):55-64.

18. Peng F. Neuroprotection effect of curcumin on 6-OHDA lesioned Parkinson's disease in rats model. Journal of Hebei North University( Medical Edition). 2010 Dec;27(6):21-3.

19. Mansouri Z, Sabetkasaei M, Moradi F, Masoudnia F, Ataie A. Curcumin has neuroprotection effect on homocysteine rat model of Parkinson. J Mol Neurosci. 2012 Jun;47(2):234-42.

20. Du XX, Xu HM, Jiang H, Song N, Wang J, Xie JX. Curcumin protects nigral dopaminergic neurons by iron-chelation in the 6-hydroxydopamine rat model of Parkinson's disease. Neurosci Bull. 2012 Jun;28(3):253-8.

21. Yu S, Wang $Y$, Wang $X$. Curcumin prevents dopaminergic neuronal death in experimental Parkinson's disease research. Journal of China Medical University. 2012 Jun;41(6):569-70.

22. Guo YX, Yang B, Shi L, Gu J, Chen H. Anti-inflammation mechanism of curcumin in mice with lipopolysaccharide-induced Parkinson's disease. Journal of Medical Postgraduates. 2012;25(6):582-7.

23. Tripanichkul W, Jaroensuppaperch EO. Ameliorating effects of curcumin on 6-OHDA-induced dopaminergic denervation, glial response, and SOD1 reduction in the striatum of hemiparkinsonian mice. Eur Rev Med Pharmacol Sci. 2013 May;17(10):1360-8.

24. Schmitz AE, de Oliveira PA, de Souza LF, da Silva DG, Danielski S, Santos DB, de Almeida EA, Prediger RD, Fisher A, Farina M, Dafre AL. Interaction of 
curcumin with manganese may compromise metal and neurotransmitter homeostasis in the hippocampus of young mice. Biol Trace Elem Res. 2014 Jun;158(3):399-409.

25. Grin IR, Konorovsky PG, Nevinsky GA, Zharkov DO. Heavy metal ions affect the activity of DNA glycosylases of the fpg family. Biochemistry (Mosc). 2009 Nov;74(11):1253-9.

26. Hegde ML, Hegde PM, Holthauzen LM, Hazra TK, Rao KS, Mitra S. Specific inhibition of NElL-initiated repair of oxidized base damage in human genome by copper and iron: potential etiological linkage to neurodegenerative diseases. J Biol Chem. 2010 Sep 10;285(37):28812-25.

27. Jung KK, Lee HS, Cho JY, Shin WC, Rhee MH, Kim TG, Kang JH, Kim SH, Hong S, Kang SY. Inhibitory effect of curcumin on nitric oxide production from lipopolysaccharide-activated primary microglia. Life Sci. 2006 Oct 19; 79(21):2022-31.

28. Huang WT, Niu KC, Chang CK, Lin MT, Chang CP. Curcumin inhibits the increase of glutamate, hydroxyl radicals and PGE2 in the hypothalamus and reduces fever during LPS-induced systemic inflammation in rabbits. Eur J Pharmacol. 2008 Sep 28;593(1-3):105-11.

29. Wang SL, Li Y, Wen Y, Chen YF, Na LX, Li ST, Sun CH. Curcumin, a potential inhibitor of up-regulation of TNF-alpha and IL-6 induced by palmitate in 3T3-L1 adipocytes through NF-kappaB and JNK pathway. Biomed Environ Sci. 2009 Feb;22(1):32-9.

30. Jaisin $Y$, Thampithak A, Meesarapee B, Ratanachamnong P, Suksamrarn A, Phivthong-Ngam L, Phumala-Morales N, Chongthammakun S, Govitrapong P, Sanvarinda Y. Curcumin I protects the dopaminergic cell line SH-SY5Y from 6-hydroxydopamine-induced neurotoxicity through attenuation of p53-mediated apoptosis. Neurosci Lett. 2011 Feb 11;489(3):192-6.

31. Chen J, Tang XQ, Zhi JL, Cui Y, Yu HM, Tang EH, Sun SN, Feng JQ, Chen PX. Curcumin protects $\mathrm{PC12}$ cells against 1-methyl-4-phenylpyridinium ioninduced apoptosis by bcl-2 mitochondria-ROS-iNOS pathway. Apoptosis. 2006 Jun;11(6):943-53.

32. Stroke Therapy Academic Industry Roundtable (STAIR). Recommendations for standards regarding preclinical neuroprotective and restorative drug development. Stroke 1999 Dec;30(12):2752-2758.

33. Fisher M, Feuerstein G, Howells DW, Hurn PD, Kent TA, Savitz SI. Lo EH; STAIR group. Update of the stroke therapy academic industry roundtable preclinical recommendations. Stroke. 2009 Jun;40(6):2244-50.

34. Yao M, Yang L, Wang J, Sun YL, Dun RL, Wang YJ, Cui XJ. Neurological recovery and antioxidant effects of curcumin for spinal cord injury in the rat: a network meta-analysis and systematic review. J Neurotrauma. 2015 Mar 15;32(6):381-91.

35. Schulz KF, Altman DG. Moher D; CONSORT group. CONSORT 2010 statement: updated guidelines for reporting parallel group randomized trials. Ann Intern Med. 2010 Jun 1;152(11):726-32.

36. Xie CL, Wang WW, Xue XD, Zhang SF, Gan J, Liu ZG. A systematic review and meta-analysis of Ginsenoside-Rg1 (G-Rg1) in experimental ischemic stroke. Sci Rep. 2015 Jan 20;5:7790.

37. Ji HF, Shen $\mathrm{L}$. The multiple pharmaceutical potential of curcumin in Parkinson's disease. CNS Neurol Disord Drug Targets. 2014a;13:369-73.

38. Shen $L$, Ji HF. The pharmacology of curcumin: is it the degradation products? Trends Mol Med. 2012 Mar; 18(3):138-44.

39. Shen L, Liu CC, An CY, Ji HF. How does curcumin work with poor bioavailability? Clues from experimental and theoretical studies Sci Rep. 2016 Feb 18;6:20872.

40. Ji HF, Shen L. Can improving bioavailability improve the bioactivity of curcumin? Trends Pharmacol Sci. 2014 Jun;35(6):265-6.

\section{Submit your next manuscript to BioMed Central and we will help you at every step:}

- We accept pre-submission inquiries

- Our selector tool helps you to find the most relevant journal

- We provide round the clock customer support

- Convenient online submission

- Thorough peer review

- Inclusion in PubMed and all major indexing services

- Maximum visibility for your research

Submit your manuscript at www.biomedcentral.com/submit
Biomed Central 